\title{
Study of the transport system and its impact on urbanized areas
}

\author{
Alexander Kryakhtunov ${ }^{1}$ and Karina Ainullina ${ }^{1, *}$ \\ ${ }^{1}$ Industrial University of Tyumen, 625001, Tyumen city, Russia
}

\begin{abstract}
Currently, the transport infrastructure plays a decisive role in the development of the city. For the development of the transport system of the territory, it is necessary to develop a whole range of measures to improve both the organization of traffic and transport infrastructure, which implies the creation of parking space, logistics of passenger and cargo transportation and other aspects. Tyumen, being a rapidly developing city and transport hub, objectively suffers from insufficient development of the road transport network. A significant problem is the congestion of the city center, which increases the travel time to the center from residential areas of the city. Therefore, it is necessary to analyze the strategic plans for the development of transport infrastructure to assess the potential of the city of Tyumen, which is rapidly approaching the status of a millionaire city, the core of a large agglomeration.
\end{abstract}

\section{Introduction}

Automobile transport has a significant impact on the development of cities, the creation of an environment convenient for life and their planning and improvement are largely determined by the conditions of car traffic. The inconsistency in the development of the city's transport system with the level of motorization disrupts the normal life of the city; therefore, the inclusion of transport infrastructure facilities in urban development is the most important urban planning task.

The process of global motorization is the introduction of cars in all types of passenger and freight transport, the spread of personal cars. The dominant role in motorization is played by cars, in connection with which the term "motorization" means the distribution of cars, and the concept of "level of motorization" means their number per 1,000 inhabitants of a settlement.

The city of Tyumen is currently a major industrial center, a transport and logistics hub, a cultural, scientific and educational center, a center of migration flows, qualified personnel and investments.

The demographic situation in the city is characterized by positive dynamics, the population as of $01 / 01 / 2020$ is 807.3 thousand people. The general plan of the urban district of the city of Tyumen, adopted in 2008, provides that the population will be 1 million people by 2040 . However, the emerging dynamics of population growth suggests that this indicator will be achieved much earlier, that is, in the next few years.

* Corresponding author: ajnullinakn@tyuiu.ru 
The age structure of the city's population is characterized by a high proportion of the working age population. Long-term plans for the development of the territory provide for the placement of objects of federal, regional and local importance in the city and the Tyumen region, in connection with which by 2040 it is expected to create at least 200 thousand new jobs in the territory of the city district and the total number of people employed in the city's economy may exceed 600. The growth of transport mobility of the business part of the population is facilitated by the development on the territory of the Tyumen municipal district, adjacent to the borders of the city of Tyumen, of low-rise housing construction for permanent residence and as a "second" housing for urban residents. Since 2008, there has been a sharp increase in the number of cars and by the current moment their number has more than doubled at the time of the study.

The city is already oversaturated with cars, as a result of which the positive characteristics of motorization have significantly weakened and at present there are negative factors - a decrease in speed due to an overload of the street network, air pollution, a high level of injuries in road accidents, an increase in population morbidity, and more. So, the average speed of movement on the territory of the city is $40-44 \mathrm{~km} / \mathrm{h}$ (excluding delays at the nodes of the transport network). Average density of passenger car traffic is 24 vehicles per $1 \mathrm{~km}$. Every day, residents lose an average of 17.4 minutes in traffic jams. It is important to note that the city of Tyumen in terms of the level of atmospheric air pollution belongs to the territory of "risk".

In addition, transport affects the area adjacent to roads and highways. On the territory of the city, there are objects of permanent and temporary storage of individual vehicles with a total capacity of about 150 thousand parking spaces, but this volume is not enough with the number of cars more than 400 thousand. The city is in need of expanding urban areas for traffic, long-term storage and temporary parking of cars.

Tyumen is an important link in transit communications in the region and across the country as a whole. To ensure economic efficiency and sustainable development, the city needs to improve its road network, taking a comprehensive approach to solving this issue, taking into account not only sociological and economic aspects, but also the impact on the ecological balance of the urban environment.

Within the boundaries of the city, it is advisable to work to identify critical points - the busiest transport hubs that have urban importance and have the highest traffic intensity. This intersection is located in close proximity to the city center and several points of attraction for the population, such as large shopping centers: Voyage, Rental, Central Department Store, Central Market, as well as Tsvetnoy Boulevard, coffee shops, and so on, which creates a colossal flow of both vehicles and pedestrians. At the same time, the conditions of passage and travel to these points of attraction and further parking of vehicles are very difficult due to the costs of organizing the territory.

\section{Methodology}

\subsection{Legal and regulatory framework for municipal management of territorial development}

The essence of urban planning activity is the development of territories, cities and other settlements, sometimes inter-settlements. Indeed, it is in urbanized areas that most of the human life is spent and here the greatest impact on the environment occurs. Urban planning activities are carried out through seven constituent elements:

- territorial planning;

- urban planning zoning; 
- planning of territories;

- architectural and construction design;

- construction of capital construction facilities;

- overhaul of capital construction objects;

- reconstruction of capital construction facilities.

The first three types of activity relate to the sphere of "working with the territory", and the next four are aimed at ensuring the creation or change of the "final product" of urban planning activity - a capital construction object. That is, the development of territories in any case begins with territorial planning, and ends, depending on the intended planning goal, either with the construction of specific objects, or it can be the creation of a specially protected natural area.

Territorial planning is defined by the Urban Planning Code of the Russian Federation as planning of territories, including for the establishment of functional zones, zones for the planned location of capital construction objects for state and municipal needs, zones with special conditions for the use of territories. At the municipal level, territorial planning documents are:

1) schemes of territorial planning of municipal districts;

2) master plans of settlements;

3) master plans of urban districts.

Spatial planning documents at the municipal level are developed and approved in the form of one (single) consolidated document. For the purposes of municipal development, it is necessary to apply an integrated approach to the development of the territory. An integrated approach is implemented in the continuous development of the territory, municipalities, without "blank spots" on the maps of general plans and schemes of territorial planning of municipal districts. At the same time, territorial planning is aimed at determining the purpose of territories based on a combination of social, economic, environmental and other factors in order to ensure sustainable development of territories, development of engineering, transport and social infrastructures, ensuring that the interests of citizens and their associations, the Russian Federation, constituent entities of the Russian Federation are taken into account, municipalities.

Special attention should be paid to the fact that territorial planning is carried out within the boundaries of municipalities established by the laws of the constituent entities of the Russian Federation. The area of the municipal formation "urban district city of Tyumen" is much larger than the settlement of "city of Tyumen", but the general plan, land use and development rules are developed and implemented within the boundaries of the urban district.

A favorable environmental situation for human life is ensured through environmental regulation, including the establishment of standards for maximum permissible concentrations, maximum permissible levels of harmful effects - which is the competence of federal executive authorities, as well as through the adoption of urban planning standards containing minimum calculated indicators for ensuring favorable living conditions person. The development and adoption of such standards is the competence of the constituent entities of the Russian Federation and local governments. Article 24 of the Town Planning Code of the Russian Federation stipulates that these standards should ensure that the specifics of various regions and municipalities are taken into account, based on the geographical, climatic, cultural and other characteristics of the territories. At the same time, the minimum calculated indicators for ensuring favorable conditions for human life at the local level cannot be lower than such indicators established at the regional level.

The territorial planning documents of the municipal level determine the provisions related to the development of the territory and arising from the powers of local selfgovernment bodies established by various federal laws: the development and placement of 
specially protected natural areas of local importance, recreational and other areas related to environmental protection and the provision of favorable life, the establishment of zones of negative impact, intended for the placement of capital development objects of local importance.

The procedure for the preparation, coordination and approval of territorial planning documents is established by the Urban Planning Code of the Russian Federation and the Instruction on the procedure for the development, coordination, examination and approval of urban planning documentation, which is valid in the part that does not contradict the Urban Planning Code of the Russian Federation.

\subsection{Characteristics of the transport infrastructure of the study area}

The city of Tyumen is a large industrial center, a transport and logistics hub, a cultural, scientific and educational center, a center of attraction for migration flows, qualified personnel, and investments. The demographic situation in the city of Tyumen over the past years has been characterized by positive dynamics, created by both natural and mechanical population growth. The city of Tyumen is attractive for internal migrants and migrants from far and near abroad at a working age. The Tyumen Municipal District attracts citizens with more environmentally friendly living conditions relative to the administrative center of the region. The age structure of the population of the city of Tyumen is characterized by a high proportion of the population of difficult age. It is reasonable to consider the complex development of the agglomeration, which is successfully implemented by the authorities of the Tyumen region and municipalities.

The socio-economic situation on the labor market of the city of Tyumen is largely due to the processes of urbanization of the adjacent territory due to the territorial proximity of settlements, the unity of the transport infrastructure. The daily labor pendulum migration of the population of the Tyumen municipal district to the city of Tyumen is about 17 thousand people. The largest percentage of workers on the territory of the city of Tyumen, residents of the Tyumen region live in rural settlements located within a 30-minute transport accessibility. Some settlements of the Moscow and Embaevsky rural settlements of the Tyumen municipal district have a common border with the city of Tyumen and a streetroad network. The population of these territories is about 20 thousand people.

The increase in the number of jobs will stimulate the growth of daily labor migration in the future. The growth of this process on a daily basis is also facilitated by the development of low-rise housing construction in the Tyumen municipal district for permanent residence and as a "second" housing for the population of the city of Tyumen. On the territory of the urban district, there are social infrastructure facilities of federal and regional significance in various areas: organizations of higher professional education, theaters, museums, a circus, medical organizations and other facilities, the services of which are actively used by residents of the Tyumen municipal district and the neighboring Sverdlovsk region. Active development of suburban areas and the concentration of public functions in the city of Tyumen will continue to stimulate the growth of transport activity. At present, the basis for the formation of the street and road network is the regular planning of the center and the fan layout of the adjacent territories along the historically established directions of the Moscow, Chervishevsky, Yalutorovsky, Velizhansky, Starotobolsky and Tobolsky tracts. The newest period of development of the street and road network of the city of Tyumen is characterized by the construction of bypasses of urban development these are the bypasses of Tyumen, connecting Velizhansky, Salairsky, Moskovsky, Chervishevsky tracts with the Yalutorovsky tract, as well as with an approach to Roshchino airport (the southern section of the bypass is part of Fedyuninsky street and Zakaluzhskaya) (Figure 1).The construction of the bypass road requires further 
development. Planned design and survey work is underway, federal and regional financial resources are being combined.

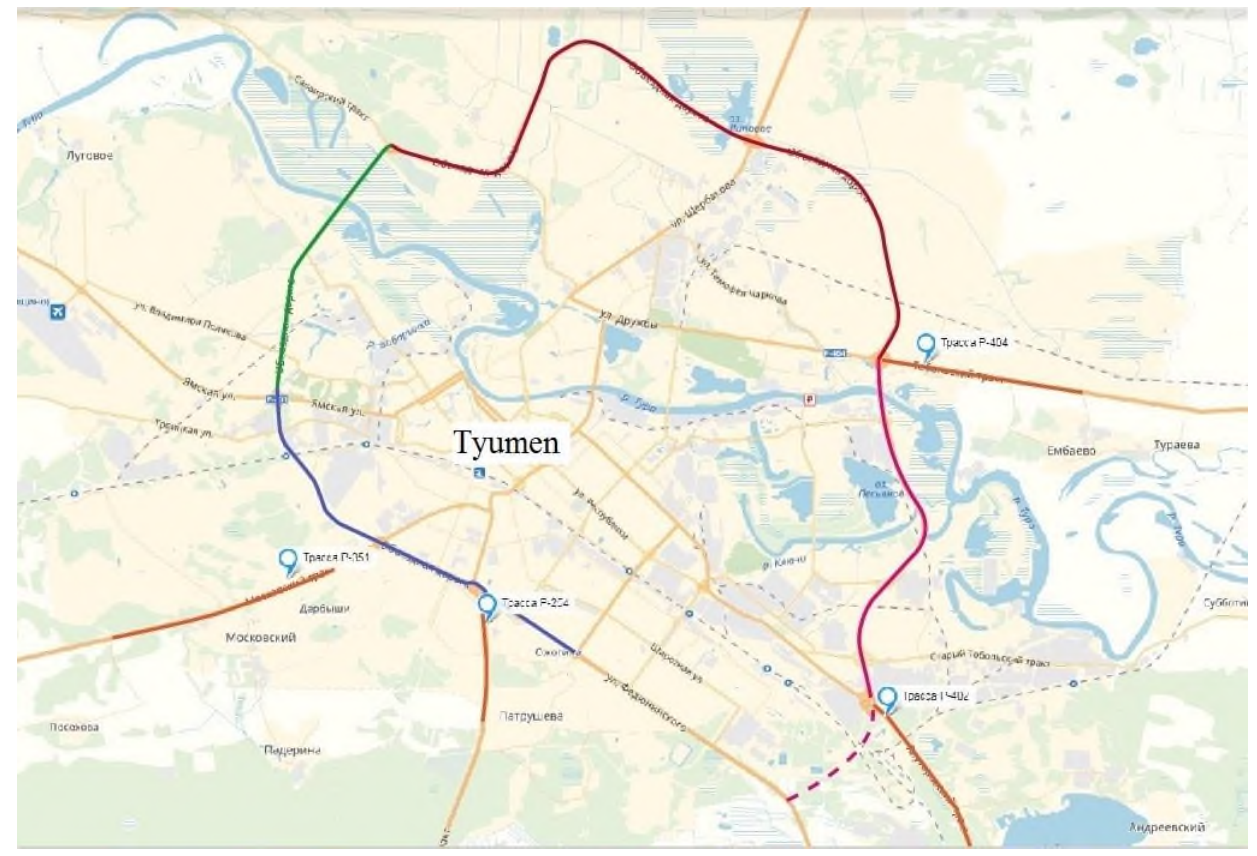

Fig. 1. Street and road network of the city of Tyumen.

The improvement of the transport infrastructure of the city of Tyumen and adjacent territories is due to the mutual disposition of residential areas and industrial areas, which provide the main places of employment. Manufacturing enterprises are located mainly in the northwestern and southeastern parts of the city. Accordingly, labor resources, industrial cargo transportation are concentrated in the direction of the federal highway R-402 (Tyumen - Ishim - Omsk). The main city-wide leisure facilities, administrative and business, public and entertainment facilities are located in the Central planning area - the historical center of the city. Dormitory areas are characterized by a significant population and jobs in trade and services. The largest number of the population lives in the Tyumen, Southern and Central planning districts, the total population in these territories is 470 thousand people, which is $65 \%$ of the total population of the urban district. Taking into account the system of resettlement and distribution of jobs, daily work and educational correspondence of residents, as well as travel for other purposes, the main areas of attraction of passenger traffic during peak hours of a weekday is the Central Planning District, in which $38 \%$ of all jobs are located, $60 \%$ of study places in higher and secondary educational institutions.

The total volume of generated correspondence during the morning rush hour is 187 thousand movements. Of these, the main part, more than $80 \%$, is movement by individual transport and public passenger transport, which moves along the road network and creates the main traffic. Movements for work purposes account for $72.5 \%$ of the total number of movements in the morning, which forms centripetal correspondence. Active urban planning processes taking place on the territory of the city determine the development of housing and industrial construction, strengthening the function of the city of Tyumen as a transport hub, as well as the need for the development of the transport system. The current general plan envisages intensive development of territories within the city boundaries. It is planned to increase the density of the existing buildings in the central part of the city, along 
the main planning axes, to provide functional saturation of the central part of the city, to develop territories not previously used for building in order to accommodate low-rise buildings. The development of the city's transport framework presupposes the creation of stable links between the existing network of streets and the forming ring system of highspeed transport routes. The development of the transport frame and its individual elements is proposed in accordance with the category of city streets and roads, established depending on the functions performed. The general plan established the following categories of streets and roads:

- main high-speed roads;

- main roads of regulated traffic;

- main streets of city-wide significance of continuous traffic;

- main streets of city-wide value of regulated traffic;

- main streets of district significance, transport and pedestrian;

- main streets of district significance, pedestrian and transport;

- streets and driveways of local importance.

High-speed trunk roads should form an external bypass transport ring with main radial directions departing from it, which will provide high-speed passage of transit traffic flows. Main streets of city-wide significance of continuous traffic and main roads of controlled traffic should form an inner transport ring with radial directions towards the outer ring, which will provide fast transport links between remote areas of the urban district, bypassing the central part of the city and a convenient exit from the city of Tyumen to the external transport network. The main streets of city-wide importance of regulated traffic should serve as the main transport arteries of the central district and the city's bordering districts. Service within the microdistricts is proposed to be carried out by main streets of regional significance, streets and thoroughfares of local significance. The main indicator of the projected road and street network is laid down in the General Plan of the urban district, the city of Tyumen. The general plan of the urban district of the city of Tyumen provides for a system of transport interchanges: at different levels - in the amount of 77 objects. Also, the General plan of the urban district of the city of Tyumen provides for the reconstruction of 3 and the construction of 13 road bridges (the construction of 1 road bridge is proposed outside the border of the urban district, the city of Tyumen on the eastern bypass), the construction of 11 road tunnels, the reconstruction of 1 and the construction of 6 pedestrian bridges, 211 pedestrian crossings in different levels with a carriageway, reconstruction 1 and construction of 76 overpasses (the construction of 8 overpasses is proposed outside the city of Tyumen on the western bypass and on highways passing along the border).

The implementation of the measures planned by the General Plan of the urban district, the city of Tyumen, will have to ensure the development of the city for a certain population, including:

- development of the road network;

- reduction of transit traffic flows through the city;

- increase in passenger traffic and freight turnover;

- increasing the capacity of the road network;

- improving traffic safety;

- continuous movement at the intersections of main streets and roads;

- strengthening of transport links between city districts;

- increasing the level of comfort and safety of pedestrian traffic;

- development of a public passenger transport network and a system of suburban intercity communication. 


\subsection{Characteristics of the transport resources of the city of Tyumen}

The transport complex of the city includes road, rail, and air transport. Road transport plays a primary role in passenger transportation, transportation of goods over short and medium distances. It occupies a leading position in urban and suburban transportation of passengers and goods, as well as in the delivery of goods to railway stations. However, road transport is more expensive than water or rail transport. Suburban, intercity and international bus service is carried out from the bus station, located at the intersection of the main highways - Respublika Street and Permyakova Street. The Tyumen bus station today is an organizing and directing link in the work of the transport system in the south of the region. Every day, passengers travel to the Tyumen region inhabited localities of the Omsk, Sverdlovsk, Kurgan, Chelyabinsk, Orenburg regions are connected with the northern districts of the Tyumen region, the Republics of Bashkortostan, Tatarstan and the Republic of Kazakhstan. The state budgetary institution of the Tyumen Region "Association of Bus Stations and Bus Stations" has contractual obligations with nine dozen road carriers, of which 34 are from other regions and states.

Railway transport in the city of Tyumen plays an important role in ensuring transport and economic ties with other regions of the country. A section of the Sverdlovsk railway runs through the territory of the urban district. The Tyumen railway junction is formed as a result of the merger of two directions: Moscow - Vladivostok and Tyumen - Surgut - NovyUrengoy. Within the boundaries of the urban district there are: passenger station Tyumen, marshalling station Voinovka, intermediate station V class Tyumen Severnaya. The main activities of the Tyumen railway junction: servicing transit traffic, servicing passenger traffic, reloading goods from other types of transport to rail and vice versa, as well as servicing industrial areas of the city through a network of access roads adjacent to the main directions and stations of the junction. Tyumen station carries out mainly passenger and intercity and suburban transportation, while Voinovka station is mainly freight.

The air transport of the city of Tyumen carries out domestic and international passenger and cargo transportation. On the territory of the city are located: airport "Roshchino", which has international status, serving international and federal lines. Airport "Roshchino" is an airport of international class, admitted to receive 23 types of aircraft and all types of helicopters. The airfield includes two artificial runways.

International airport "Roshchino" serves more than 40 destinations, on which 16 airlines operate regular and charter flights. Plekhanovo airport is the base airport for UTair airlines. Located in the southwestern part of the city of Tyumen, $8 \mathrm{~km}$ from its center. In the future, it is planned to relocate the Plekhanov airport.

\subsection{Characteristics of the road network of the city of Tyumen}

The length of roads within the boundaries of the city of Tyumen is $1,326.8 \mathrm{~km}$ (federal significance - $3.7 \mathrm{~km}$, regional and intermunicipal significance - $117.7 \mathrm{~km}$, local significance - $1205.4 \mathrm{~km}$ ). The length of the city's road network is $1205.4 \mathrm{~km}$. Today, a significant part of the streets in low-rise residential buildings (37\%) do not have capital road pavement. The length of entrances to horticultural, vegetable gardening and dacha non-profit associations of citizens is about $130 \mathrm{~km}$. In them there are only $42 \%$ of streets with capital-type pavement. The composition of the traffic flow on the territory of the city of Tyumen does not change significantly in sections and in time of day. The leading positions in the traffic flow are occupied by individual cars, their share is $75-90 \%$. The busiest sections include overpasses across the railway, a section of a bypass road on the section from Moskovsky trakt street to Avtoremontnaya street. The intensity of passenger car traffic in the most congested areas exceeds 2,500 passenger cars per hour. The average 
speed in the city is about $40 \mathrm{~km} / \mathrm{h}$ without taking into account delays at network nodes, along the main road network of about $44 \mathrm{~km} / \mathrm{h}$ without taking into account delays at network nodes. The traffic density of passenger cars is 24 passenger cars per $1 \mathrm{~km}$. In the morning rush hour, cars move in a continuous stream at low speeds. The average load on the backbone road network is $88 \%$. At a load level of $90 \%$ and above, the traffic flow moves with stops, and congestion occurs.

The annual volume of emissions of pollutants from road transport has a steady upward trend. The main reason for the growing volume of emissions is the periodically increasing level of motorization in the city, as well as the peculiarities of urban traffic: relatively low speeds, frequent changes in direction and speed of movement, accompanied by repeated braking and acceleration, short transportation distances, which cause the engines to operate mainly in unsteady thermal conditions. The specified operating conditions of the car are significantly aggravated with an increase in traffic density.

In terms of air pollution levels (from 2 to 5 maximum permissible concentration), the city of Tyumen belongs to the territories of "risk". Traffic flows are concentrated mainly in the central part of the city of Tyumen. A critical situation develops at the intersection of high-traffic main streets during the hours of maximum traffic and the main highways of urban importance. In addition, transport has a huge impact on the area adjacent to roads and highways. Air quality control in the city of Tyumen is carried out by three independent organizations: stationary control posts of the national observation system of the Tyumen Center for Hydrometeorology and Environmental Monitoring; the state institution "Center for Hygiene and Epidemiology in the Tyumen Region"; mobile laboratory "LesParkKhoz".

The increase in air pollution is mainly due to an increase in the traffic load on the central districts of Tyumen. The increase in the number of vehicles and the reconstruction of the city's highways inevitably leads to a reduction in special-purpose green spaces along the streets and roads. When the carriageway is widened, the protective landscaping is demolished, which is the main barrier between traffic noise, dust, emissions and pedestrians. To reduce the negative impact of road transport on the environment, it is necessary to envisage not only the optimization of traffic flows, but also to organize a system of green spaces along the highways that perform protective functions. The transport infrastructure of the city of Tyumen is an integral part of the city transport system.

\section{Results and discussion}

\subsection{Target indicators of motorization}

The general plan of the Tyumen city district defines the target indicators of the city's motorization: by 2025 - 480 cars / 1 thousand people, by 2040 - 510 cars / 1 thousand people.

Upon reaching the planned level of motorization by 2040, the average speed will be 45 $\mathrm{km} / \mathrm{h}$. On main streets $-60 \mathrm{~km} / \mathrm{h}$. The density of the traffic flow will decrease by 20 cars per $1 \mathrm{~km}$.

To create a single parking space by 2040 , it is planned to build and reconstruct longterm storage places for cars in the amount of 262 thousand parking spaces, as a result, the total number of parking spaces in the city should be 412 thousand units.

For the estimated period, it is planned to use public passenger transport and nonmotorized vehicles, which will increase the efficiency of the transport system (Table 1). 
Table 1. Rough forecast of the distribution of movements by mode of transport.

\begin{tabular}{|c|c|c|c|c|c|}
\hline Transport system & 2020 year & $\begin{array}{l}\mathbf{2 0 2 5} \\
\text { year }\end{array}$ & $\begin{array}{c}\mathbf{2 0 3 0} \\
\text { year }\end{array}$ & $\begin{array}{c}\mathbf{2 0 3 5} \\
\text { year }\end{array}$ & $\begin{array}{l}\mathbf{2 0 4 0} \\
\text { year }\end{array}$ \\
\hline Individual transport & $41 \%$ & $35 \%$ & $35 \%$ & $35 \%$ & $31 \%$ \\
\hline Public passenger transport & $42 \%$ & $48 \%$ & $50 \%$ & $52 \%$ & $55 \%$ \\
\hline Walking and cycling & $17 \%$ & $17 \%$ & $15 \%$ & $13 \%$ & $14 \%$ \\
\hline
\end{tabular}

A decrease in the share of individual transport is impossible even in connection with the planned increase in the volume of transport movements of the population within the city and urban agglomeration. The task of organizing effective transport provision of the population cannot be solved only by increasing the share of public transport and creating conditions for walking and cycling.

Measures to achieve the target indicators of the city's motorization are focused on the development of transport infrastructure according to the option of developing combined mobility, or "City Convenient for Life". It is planned to use public and private transport in a comprehensive manner, including the creation of high-speed transport lines, the organization of transport hubs, an increase in the proportion of pedestrian and bicycle movements, the creation of conditions for the organization of a single parking space, including the gradual and complete elimination of free parking in the central part of the city in the territories common use.

Thanks to the adopted and ongoing programs in the field of transport infrastructure development, the city of Tyumen is already in the lead in the rating of Russian cities in terms of the quality of the transport system as a whole, in terms of the quality of roads and parking lots, and this trend will continue in the near future.

Thus, the measures provided for by strategies, plans and programs are aimed at optimizing the level of motorization in Tyumen and improving the comfort of the urban environment as a whole.

The development of the transport infrastructure of the city of Tyumen is provided by:

- Main streets of city-wide significance of continuous traffic and main roads of controlled traffic should form an inner transport ring with radial directions towards the outer ring, which will provide fast transport links between remote areas of the city district, bypassing the central part of the city of Tyumen and a convenient exit from the city of Tyumen to the outer transport network.

- The main streets of city-wide importance of regulated traffic should serve as the main transport arteries of the central district and the bordering districts of the city of Tyumen.

- Service within the microdistricts is proposed to be carried out by main streets of regional significance and streets and driveways of local significance.

- The main indicator of the projected road network is the total length of the road network - $1217.8 \mathrm{~km}$, including high-speed main roads $-91.7 \mathrm{~km}$; a road of ordinary type of regional significance $-9.1 \mathrm{~km}$; main roads of regulated traffic $-41.9 \mathrm{~km}$; main streets of city-wide significance, continuous traffic - $10.5 \mathrm{~km}$; main streets of city-wide significance, regulated traffic - $144.8 \mathrm{~km}$; main streets of district significance, transport and pedestrian $229.6 \mathrm{~km}$; streets and local roads - $690.2 \mathrm{~km}$.

- improving the quality and efficiency of transport services for the population and economic entities;

- ensuring the safety of transport services for the population and economic entities;

- limiting the negative impact on the environment and human health.

As a result of the implementation of the plan for the development of the transport infrastructure of the urban district and urban agglomeration, the above tasks will be solved. 
An obligatory element in planning the development of the transport infrastructure of the city of Tyumen is the territorial planning document - the General plan of the urban district of the city of Tyumen.

The general plan of the Tyumen city district provides for the concentric territorial development of the city with the formation of a radial-circular transport and planning structure due to the completion of the formation of a short road bypass of the city of Tyumen, within which the bulk of new construction will be carried out. In the future, it is planned to build a long-distance road bypass, which will limit all areas of the existing and prospective development.

\section{Conclusion}

The main requirements for the development of the transport infrastructure of the city of Tyumen are established by the General plan of the urban district of the city of Tyumen, which determines the planning organization of the territory, which divides the street-road network into its support and local subsystems. In the development of the decisions of the General plan of the urban district of the city of Tyumen, planning projects of all the city's territories were approved, which, with red lines, established clear boundaries of all elements of the road network, taking into account the development of all types of transport: road transport, public passenger transport, bicycle and pedestrian. Specific requirements for the elements of transport infrastructure are established by regional and local regulations for urban planning. Thus, the minimum required regulatory and legal framework for the functioning and development of transport infrastructure in the city of Tyumen has been formed.

\section{References}

1. Urban planning code of the Russian Federation 